\section{Serological diagnosis of mumps}

Experience over the years at this laboratory, using both antigens supplied by the Standards Laboratory, Colindale, and antigens prepared here, confirms the report by Drs $R$ Freeman and $\mathrm{MH}$ Hambling (January 1980, p 28). Thus even the first edition of our book ${ }^{1}$ carried the following statement: 'It has been claimed that antibodies to the $S$ antigen increase earlier after infection than antibodies to the $\mathrm{V}$ antigen (Henle et al., 1948), but we have been unable to confirm this.'

NR GRIST Regional Virus Laboratory, Ruchill Hospital, Glasgow G20 9NB

\author{
Reference \\ 1 Grist NR, Ross CAC, Bell EJ, Stott EJ. \\ Diagnostic Methods in Clinical Virology. \\ 1st ed. Oxford: Blackwell, 1966:63.
}

\section{Histological diagnosis and prognosis of malignant melanoma}

Dr Levene's article (February issue, pp 101-124) is a valuable account of the features to be seen in this field. It will serve as a useful bench reference, not only for the occasional encounter with these lesions, but, since it has useful indicators for the less commonly seen points of diagnosis, also for those dealing regularly with them. The illustrations of the lymphatic involvement in naevi are a case in point; it is reassuring to know that this feature is clinically innocent.

In spite of all the features indicated, there are still cases which produce diagnostic headaches, even in centres that deal with significant numbers of melanomas. This laboratory sees at least one new case of primary cutaneous malignant melanoma each week; numerous benign naevi and small numbers of blue and Spitz naevi are also seen. As an aid to diagnosis we not only adopt the methods described by Dr Levene but also utilise reticulin impregnation on occasions. McGovern ${ }^{1}$ stresses the help that such preparations can give; latterly he appears to be less enthusiastic. ${ }^{2}$ As a result a study of this technique was undertaken. ${ }^{3}$ In essence, it seldom gives information not obtainable by careful assessment of good haematoxylin and eosin sections, and it should never be used to overturn the diagnosis of malignancy as assessed by the more usual criteria. However, it can prove useful in some cases of Spitz naevi where a very comforting benign pattern can be demonstrated, ie, a completely, or almost completely, preserved epidermal basement membrane and neat clusters of reticulin-surrounded cells in the deep parts of the lesion. Within its limitations it is a useful technique in this field.

JAMES C BRIGGS

Department of Pathology, Frenchay Hospital, Bristol BSI6 1LE

\section{References}

${ }^{1}$ McGovern VJ. Malignant Melanoma, Clinical and Histological Diagnosis. John Wiley and Sons, 1976.

${ }^{2}$ McGovern VJ. Personal communication. 1979.

${ }^{3}$ Briggs JC. Reticulin impregnation in the diagnosis of malignant melanoma. Histopathology 1980, in press.

Urinary infection with coagulase-negative staphylococci in patients undergoing prostatectomy

Urinary tract infections due to coagulasenegative staphylococci of biotypes SII-VI ${ }^{1}$ are seen mainly in elderly male hospital patients associated with instrumentation or an underlying lesion of the urinary tract. ${ }^{2}{ }^{3}$ Coagulase-negative staphylococci isolated in significant numbers from urine collected during one year from patients undergoing prostatectomy were classified according to the scheme of Kloos and Schleifer. ${ }^{4}$

The patients studied were those undergoing open prostatectomy or transurethral resection of the prostate, but any receiving antibiotics were excluded. None of the patients had in fact received any local or systemic antibacterial agents at any time. Patients with acute retention had been managed initially by urethral catheterisation and closed bladder drainage and had an indwelling catheter in situ when they went for operation. All the patients were catheterised postoperatively.

Midstream urine samples (or if an indwelling catheter was present aspiration from the catheter tubing) were collected daily. The specimens were refrigerated within minutes of collection and were later plated in the laboratory on MacConkey agar (Oxoid CM7B) using a standard loop. Significant bacteriuria was defined as more than $10^{5}$ organisms $/ \mathrm{ml}$ urine but lower counts were regarded as significant in a catheter specimen if the organism persisted. Pyuria was not included in the diagnosis of infection because of the inevitable haematuria that follows surgery. Coagulase-negative staphylococci were identified by Gram-stain, glucose fermentation, and failure to produce free coagulase. Sensitivity to novobiocin was tested using $5 \mu \mathrm{g}$ strength discs. Commercially prepared galleries containing 19 biochemical tests, based on the criteria of Kloos and Schleifer ${ }^{4}$ for biotyping coagulase-negative staphylococci, were inoculated with suspensions of each isolate and incubated for 24 hours at $37^{\circ} \mathrm{C}$. The typing codes were compared to the system prepared for the identification of staphylococci by the API Systems SA (Montalieu Vercieu, France). Sensitivity testing was carried out using the method described by Stokes. ${ }^{5}$

The incidence of pre-prostatectomy significant bacteriuria was higher in patients catheterised before operation. ${ }^{6}$ De novo infections were defined as postoperative significant bacteriuria in patients in whom the urine preoperatively was sterile. ${ }^{7}$ Fourteen strains of coagulasenegative staphylococci were isolated, all of which fermented glucose and were sensitive to novobiocin. The Table shows their identification by the API scheme. Although coagulase-negative staphylococci were not commonly isolated from pre-prostatectomy bacteriuria, they were the second most common cause (after enterococci) of post-prostatectomy de novo infection. Four out of five strains of coagulase-negative staphylococci which caused preoperative bacteriuria and eight out of nine coagulase-negative staphylococci from post-prostatectomy de novo infection were Staphylococcus epidermidis. The ages of the men with Staph. epidermidis urinary infections ranged from 53 to 84 years. Our findings suggest that just as Staph. saprophyticus (Micrococcus type 3 ) has a predilection for the urinary tract of young women ${ }^{8}$ so Staph. epidermidis has a predilection for the urinary tract of elderly male inpatients with prostatic obstruction who undergo prostatectomy.

Bultitude and Eykyn ${ }^{9}$ found that the most common organisms that colonised the fossa navicularis in patients undergoing prostatectomy were coagulasenegative staphylococci, and Brehmer and Madsen $^{10}$ showed that the main route of bladder infection in catheterised males is 